\title{
New Technique for Speciation of Uranium in Sediments Following Acetate-Stimulated Bioremediation
}

\author{
Nikki Peck \\ Office of Science, Science Undergraduate Laboratory \\ Internship Program \\ Harvey Mudd College \\ Stanford Linear Accelerator Center National Accelerator Laboratory \\ Menlo Park, CA
}

August 13, 2010

Prepared in partial fulfillment of the requirement of the Office of Science, Department of Energy's Science Undergraduate Laboratory Internship under the direction of John Bargar in the Molecular and Environmental Interface Science department at the Stanford Linear Accelerator Center.

Participant:

Signature

Research Advisor:

Signature 


\section{TABLE OF CONTENTS}

Abstract

iii

Introduction

1

Materials and Methods

3

Results

6

Discussion and Conclusion

7

Acknowledgements

8

References

8

Figures

10 


\section{ABSTRACT}

New Technique for Speciation of Uranium in Sediments Following Acetate-Stimulated Bioremediation, NIKKI PECK (Harvey Mudd College, Claremont, CA 91711) JOHN BARGAR (SLAC National Accelerator Laboratory, Menlo Park, CA 94025)

Acetate-stimulated bioremediation is a promising new technique for sequestering toxic uranium contamination from groundwater. The speciation of uranium in sediments after such bioremediation attempts remains unknown as a result of low uranium concentration, and is important to analyzing the stability of sequestered uranium. A new technique was developed for investigating the oxidation state and local molecular structure of uranium from field site sediments using X-Ray Absorption Spectroscopy (XAS), and was implemented at the site of a former uranium mill in Rifle, CO. Glass columns filled with bioactive Rifle sediments were deployed in wells in the contaminated Rifle aquifer and amended with a hexavalent uranium (U(VI)) stock solution to increase uranium concentration while maintaining field conditions. This sediment was harvested and XAS was utilized to analyze the oxidation state and local molecular structure of the uranium in sediment samples. Extended X-Ray Absorption Fine Structure (EXAFS) data was collected and compared to known uranium spectra to determine the local molecular structure of the uranium in the sediment. Fitting was used to determine that the field site sediments did not contain uraninite $\left(\mathrm{UO}_{2}\right)$, indicating that models based on bioreduction using pure bacterial cultures are not accurate for bioremediation in the field. Stability tests on the monomeric tetravalent uranium (U(IV)) produced by bioremediation are needed in order to assess the efficacy of acetate-stimulation bioremediation 


\section{INTRODUCTION}

The production of uranium (U) for power generation and defense has led to contamination at many locations across the country [1]. One of the proposed methods for remediating contaminated groundwater hinges on the use of microbes to reduce soluble metallic ions into insoluble forms. Of particular interest is the reduction of hexavalent $U(U(V I))$ into tetravalent $\mathrm{U}(\mathrm{U}(\mathrm{IV}))$. $\mathrm{U}(\mathrm{VI})$ is very toxic and very soluble, while $\mathrm{U}(\mathrm{IV})$ is much less soluble and thus less mobile in ground water [2]. Current models assume that this reduction results in the production of biogenic uraninite, $\mathrm{UO}_{2+\mathrm{x}}, 0 \leq \mathrm{X} \leq .25$ [3]. Due to its relative stability and insolubility, uraninite is thought to have great potential as a means of sequestering subsurface $U$ contamination [4]. However, the actual speciation; that is, the chemical and physical form, oxidation state and local molecular structure of bioremediated uranium at contaminated sites remain unknown as a result of its complex biogeochemistry. Identifying this speciation is vital to understanding the stability of the reduced uranium and thus analyzing the efficacy of bioremediation attempts. Uranium speciation as a result of acetate-stimulated bioremediation, as well as its variation through time, was investigated through in situ U(VI) reduction in field tests at a former uranium mill in Rifle, CO.

Typical bioremediation techniques rely on the reduction of U(VI) into U(IV) by microbes like Geobacter species [5]. Electron donor molecules like acetate or ethanol are injected into the ground water source to generate anoxia and thus create optimal reducing conditions [3].

Microbes then mediate the reduction of electron receptors like $\mathrm{NO}_{3}{ }^{-}, \mathrm{Fe}(\mathrm{III}), \mathrm{SO}_{4}{ }^{2-}$ and, most notably, U(VI). Microbial reduction at the field site can be thought of as proceeding in two main stages: iron and sulfate reduction. Reduction of U(VI) has been found to decrease dramatically upon the transition from iron to sulfate reduction, inspiring a need for investigation of how uranium speciation varies through these stages. 
The field site used for this experiment is located in Rifle, $\mathrm{CO}$, at the site of a former uranium mill. As a result of the Uranium Mill Tailings Remedial Act, contaminated soil was removed and disposed of, but up to $0.17 \mathrm{mg} / \mathrm{L}$ uranium [6] remains in the alluvial aquifer below the site. Acetate, $\mathrm{CH}_{3} \mathrm{COO}^{-}$, has been injected in the groundwater at the Rifle site to serve as an electron donor for microbial bioremediation as per the following expected reaction:

$$
\begin{gathered}
0.125 \mathrm{CH}_{3} \mathrm{COO}^{-}+0.775 \mathrm{UO}_{2}^{++}+0.3538 \mathrm{H}_{2} \mathrm{O}+0.0113 \mathrm{NH}_{4}^{+}=0.0113 \mathrm{BM}-\text { _iron }+0.775 \\
\mathrm{UO}_{2}(\mathrm{~s})+0.855 \mathrm{H}^{+}+0.1938 \mathrm{HCO}_{3}{ }^{-}[3]
\end{gathered}
$$

This research focuses on determining what form of uranium is produced by acetate stimulated bioremediation at the Rifle site. Though models predict that bioremediation will produce uraninite as a final product, the products of bioremediation in the field remain unknown as a result of the extremely low concentrations of uranium in treated sediments. Background uranium concentration in sediments is approximately five parts per million, while the Extended X-ray Absorption Fine Structure detection limits is approximately fifty parts per million. However, the use of novel in-well sediment columns allows for investigation of the products of microbial metal reduction in various conditions by permitting the addition of uranium and other influent solutions without fear of harm to the environment.

The in-well reactor column setup used at the Rifle, CO site operates by pulling groundwater through a glass column full of bioactive sediment from the Rifle site, as shown in Figure 2. Uranium is amended into the influent groundwater, eliminating the previous issue regarding uranium concentration in sediments being too low for analysis using spectroscopic methods. In August 2010, we deployed twenty-two in-well columns in two different wells at the Rifle site, wells CD-04 and CD-11. Figure 1 illustrates the flow cell and well setup at the Rifle site. The CD-11 columns were also subject to a bicarbonate injection, to investigate the effect of bicarbonate on uranium speciation as well. Once sediment had been harvested, X-ray Absorption 
Spectroscopy (XAS) was used to discern both the local and compound-scale structure of the reduced uranium from the columns, and thus to answer the overarching question of what is produced during acetate stimulated bioremediation. In particular, this experiment is concerned with the products of stimulated sediment bioremediation during iron and sulfate reduction.

\section{MATERIALS AND METHODS}

\section{i. Experimental Apparatus}

The experimental apparatus consists of a number of glass columns (Kontes chromatography columns) affixed to a PVC pipe and inserted into a well at the Rifle site. Two peristaltic pumps (Ismatec) are also utilized in the column setup. One pump draws effluent groundwater out of the column at $0.2 \mathrm{~mL} / \mathrm{min}$, while the other amends uranium stock solution into the groundwater flowing through a column at $.02 \mathrm{~mL} / \mathrm{min}$ to provide an approximate ten to one dilution. The uranium stock solution consisted of $200 \mathrm{uM} \mathrm{U}(\mathrm{VI})$, as well as some additional acetate to ensure that microbial stimulation is achieved. The columns themselves, shown in Figure 1, are filled with sediment and contain a single inlet line on the bottom of the column and an outlet line on top. Fourteen of these columns are affixed to a PVC pipe via cable ties and submerged in Rifle well CD-04 at depths from 22 to 16 feet below ground level, while another eight of these columns are similarly submerged in Rifle well CD-11. At the outlet of each column, a length of polyethylene (PE) tubing connects to the outlet and travels up the well to approximately one foot below the water line, where it then connects to approximately 16 feet of stainless steel tubing. 1/8 inch stainless steel tubing is used above the water line because of its low oxygen diffusivity. The stainless steel tubing then connects to the effluent peristaltic pump outside of the well. Tubing from the influent pump connects to stainless steel and PE tubing just as with the effluent pump. Once at the column itself, the influent tubing is connected to a tee, 
which in turn connects to a length of PE tubing drawing groundwater from 17 feet below ground level through a one way valve, and two feet of PE tubing connecting to the inlet of a column. The two feet of PE tubing provides sufficient length to allow for mixing of groundwater with the amended uranium via diffusion. The one way valve prevents the uranium amendment from leaking into the groundwater. In order to enforce anoxia, the influent peristaltic pump is sealed inside of a glove bag inflated with a gas mixture of nitrogen and 5\% carbon dioxide, and bottles containing influent solution were filled with the same gas mixture. The gas mixture was divided between two glove bags and three bottles of influent solution via stainless steel tees, and several plug valves were used as flow control devices.

\section{ii. Experimental Setup and Procedure}

Setup of this experiment consisted of three main steps: assembly of the in-well reactors, column packing, and tube priming. Assembly of the in-well reactors involved connecting different tubing types, putting together the columns themselves, and attaching columns and their associated tubing to a $3 / 4$ inch PVC pipe. Connections between different pieces of $1 / 8$ inch tubing were made using a slightly larger piece of soft tubing, specifically $3 / 32$ inch inner diameter Tygon tubing. A small piece of such tubing, when stretched over 1/8 inch outer diameter polyethylene or stainless steel tubing, was able to effectively connect the two tubing types without fear of leakage or air incursion. The columns themselves were assembled as per the instructions provided by their manufacturer, with one small alteration. In order to prevent the flow of fine sediment particles through the column and into the tubing, the filters included in the columns were removed and replaced with a small circle of nylon organza. Upon assembly, the columns were attached to a 20 foot PVC pipe via 14 inch cable ties tied through holes drilled in the pipe. As a result of the four inch diameter of the wells, it was necessary for two columns to be affixed next to each other, and for each set of two columns to be in line with the set below, as 
diagrammed in Figure 3. Column packing refers to the process by which the columns were filled with sediment. In order to assure even flow and to decrease the number of air bubbles present in the system, the columns need to be filled very thoroughly with as much sediment as possible. This was attained by creating a slurry of sediment and water, and gently tapping any air bubbles out of the column while pumping water through the filled column with one of the peristaltic pumps. Finally, every length of tubing used in the setup needed to be primed to ensure that as little air as possible was introduced to the system. The priming process involved first running water in both directions, through both the influent and the effluent lines using a large groundwater pump. Following this, groundwater was pumped through each influent line with an Ismatec peristaltic pump until water was seen dripping out the effluent line.

Upon deployment into the wells at the Rifle site, the in-well column setup was simply allowed to remain in the well with a constant flow of groundwater through each column. Different columns were harvested at different time points, to give a time-dependent view of uranium speciation under acetate stimulation. Table 1 demonstrates the nominal harvest time of each column, although these times are subject to change based on whether the occurrence of iron reduction or sulfate reduction is detected.

\section{iii. Sample Preparation}

Samples collected from the column reactors for analysis via XAS techniques are both highly oxygen sensitive and radioactive and, as a result, were handled with extreme care. The samples were shipped from the Rifle site in stainless steel vacuum containers, and all sample preparation occurred within an anaerobic glove box marked as a contamination area. Sediment samples were transferred into centrifuge tubes via pipette, and then centrifuged for several minutes to force the sediment to separate from any water in the sample. The sediment was then carefully transferred into aluminum sample holders and covered with kaptan tape to prevent any sediment from 
escaping while minimizing x-ray intensity loss. Once loaded into the beam hutch, a liquid nitrogen cryostat was used to maintain a vacuum on the sample and prevent any incursion of oxygen.

iv. X-ray Spectroscopy

Analysis of these samples relies on X-ray spectroscopic techniques. In particular, x-ray absorption near edge spectroscopy (XANES) and x-ray absorption fine structure spectroscopy (EXAFS) are utilized to discern the oxidation state and local molecular structures of the reduced uranium in the samples. These well-known techniques [7] were combined to provide a view of the oxidation state and local atomic structure of the uranium in the samples. Analysis of the spectroscopic results was performed using SixPack to process the resulting spectra and fit the results to the most probable crystal configuration.

\section{RESULTS}

XAS was performed on sediment samples from experimentation in the summer of 2009 in wells P-101 and P-102. Figure 4a depicts the spectrum produced by XAS at beam line 11-2 at SSRL for sediment taken from the column from well P-101. Figure 4c shows the spectrum produced by sediment taken from the sediment from well P-102. Figures $4 \mathrm{~b}$ and $4 \mathrm{~d}$ shown the Fourier transformed spectra for the sediment samples, with fits from SixPack. The low concentration of uranium in the samples, even after amendment, limits the resolution of the data collected. Each of these spectra indicates the structure of the uranium complexes present in the columns after acetate-stimulated bioreduction.

\section{DISCUSSION AND CONCLUSION}


As illustrated in Figures 4a-4d, spectra from XAS on sediments from columns deployed in Rifle wells P-101 and P-102 in 2009 show clear resemblance to one another, implying that the speciation of uranium is independent of from which well the column sediment is harvested. Data analysis and fitting using SixPack, shown in Figures $4 a-4 d$, also reveal that the reduced uranium products are not uraninite, the spectrum for which is illustrated in Figure 5. Indeed, the most probable fits suggest that these uranium products are bonded with calcium and phosphorus, or possibly adsorbed onto iron biomass. The implications of these results are quite significant to bioremediation attempts at sites like Rifle. Acetate-stimulated bioreduction of uranium has been modeled as producing uraninite, but these results clearly display that this is not the case in Rifle groundwater. Rather, U(IV) appears to form complex structures including phosphorus and possibly calcium or iron. With uraninite seemingly serving no role in this reduction process, it is clear that uraninite cannot be used as a means of sequestering uranium from contaminated groundwater.

Further study is needed to fully understand the bioreduced structure of uranium. Limited resolution as a result of low uranium concentration makes determining the exact identity and locations of the atoms bonded to uranium impossible; hence, the addition of further uranium is a necessary step for improvement. Sediment samples from the 22 columns deployed in August 2010 are intended to provide further information about uranium speciation after acetate stimulation, specifically during iron and sulfate reduction.

\section{ACKNOWLEDGEMENTS}

This work was made possible by the Stanford Synchrotron Radiation Light Source at the Stanford Linear Accelerator Center National Accelerator Laboratory, the Department of Energy, the United States Geological Study and the city of Rifle. I would like to thank my mentor, John 
Bargar, as well as Patricia Fox, Jim Davis, Jose Cerrato, Carolyn Sheehan, Sung-Woo Lee, Mike Massey, Marc Michel, Joanne Stubbs, Juan Lezama, Cynthia Patty, and Carol Morris for their invaluable assistance.

\section{REFERENCES}

[1] Riley, R.G., Zachara, J.M., Wobber, F.J., "Chemical Contaminants on DOE Lands and Selection of Contaminant Mixtures for Subsurface Science Research," U.S. Department of Energy, 1992.

[2] Langmuir, D., "Uranium solution-mineral equilibria at low temperatures with applications to sedimentary ore deposits," Geochimica et Cosmochimica Acta, vol. 42, no. 6, pp. 547-569, 1978.

[3] Yabusaki, S.B., Fang, Y., Long, P.E., et al., "Uranium removal from groundwater via in situ biostimulation: Field-scale modeling of transport and biological processes," Journal of Contaminant Hydrology, vol. 93, no. 1-4, pp. 216-235, 2007.

[4] Bargar, J., Bernier-Latmani, R., Giammar, D., et al., "Biogenic Uraninite Nanoparticles and Their Importance for Uranium Remediation,” Elements, vol. 4, pp. 407-412, 2008.

[5] Anderson, R., Vrionis, H., Ortiz-Bernad, I., et. al, "Stimulating the In Situ Activity of Geobacter Species To Remove Uranium from the Groundwater of a Uranium-Contaminated Aquifer," Applied Environmental Microbiology, vol. 69, no. 10, pp. 5884-5891, 2003.

[6] "Ground Water Compliance Action Plan for the Old Rifle, Colorado, UMTRA Project Site," U.S. Department of Energy, document no. U0066302, 2001.

[7] Kelly, S.D., Hesterberg, D., Ravel, B., “Analysis of Soils and Minerals Using X-ray Absorption Spectroscopy in Methods of Soil Analysis, Part 5 -Mineralogical Methods, Ulery and A.L., Drees, L.R., Eds., Madison, WI: Soil Science Society of America, 2008. 


\section{FIGURES}

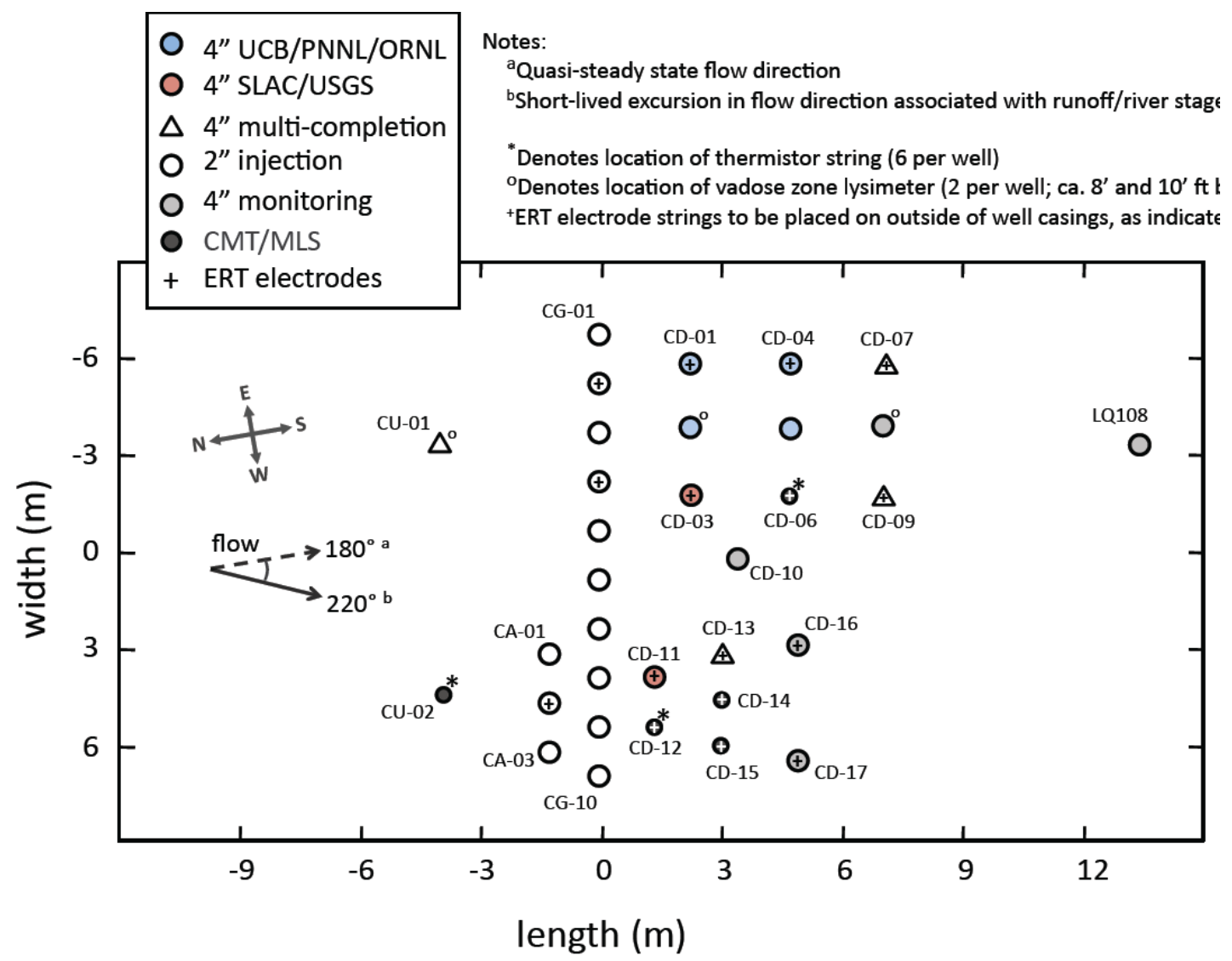

Figure 1: The flow cell and well setup at the Rifle site. The wells used in this experiment were wells CD-04 and CD-11. The designation "CD" refers to the location of the wells as being downstream of the injection sites ("D") and in experimental plot C. 


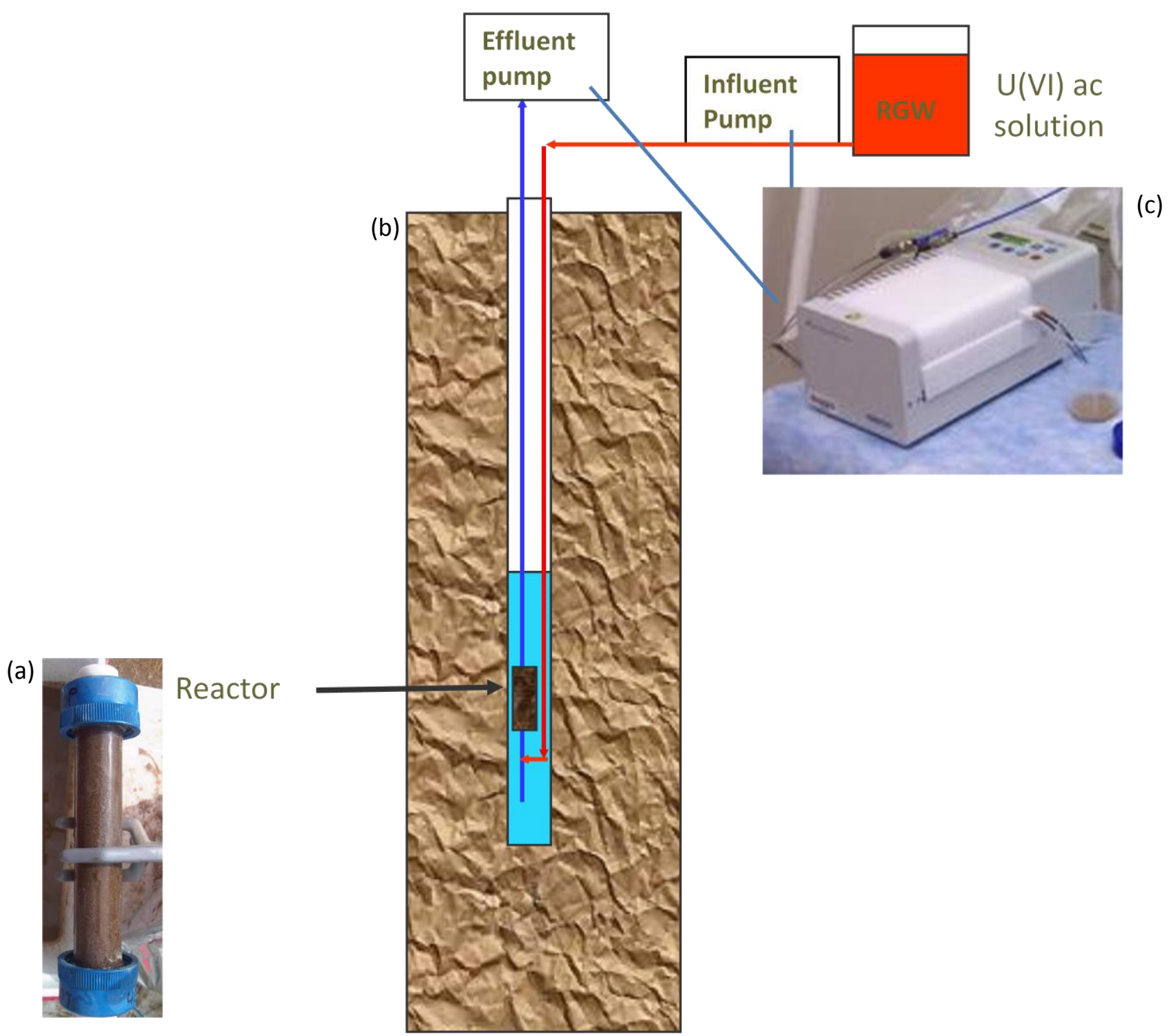

Figure 2: The in situ column setup. (a) One in situ column, filled with bioactive Rifle sediment. (b) A schematic of a Rifle well demonstrating the flow of U(VI) stock solution into the column and ground water out of the column. (c) One of the peristaltic pumps utilized in the setup. 


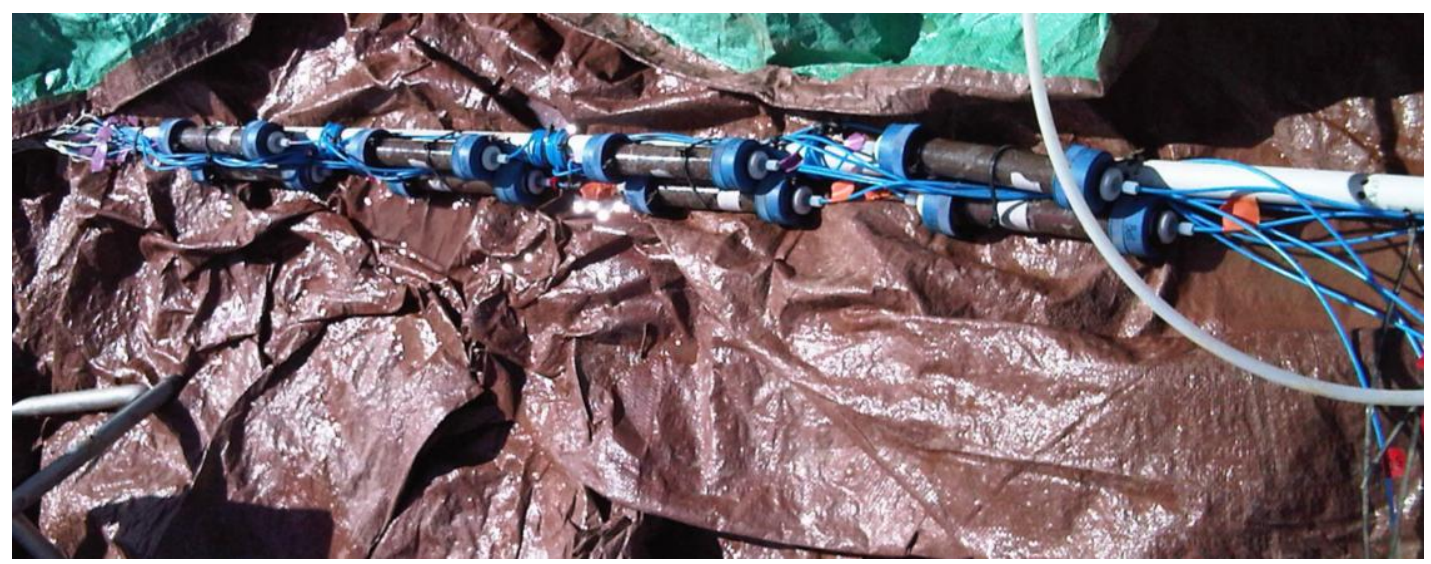

Figure 3: The in-well column setup. The columns are the blue-capped cylinders and are shown filled with sediment. The blue tubing is polyethylene tubing. 


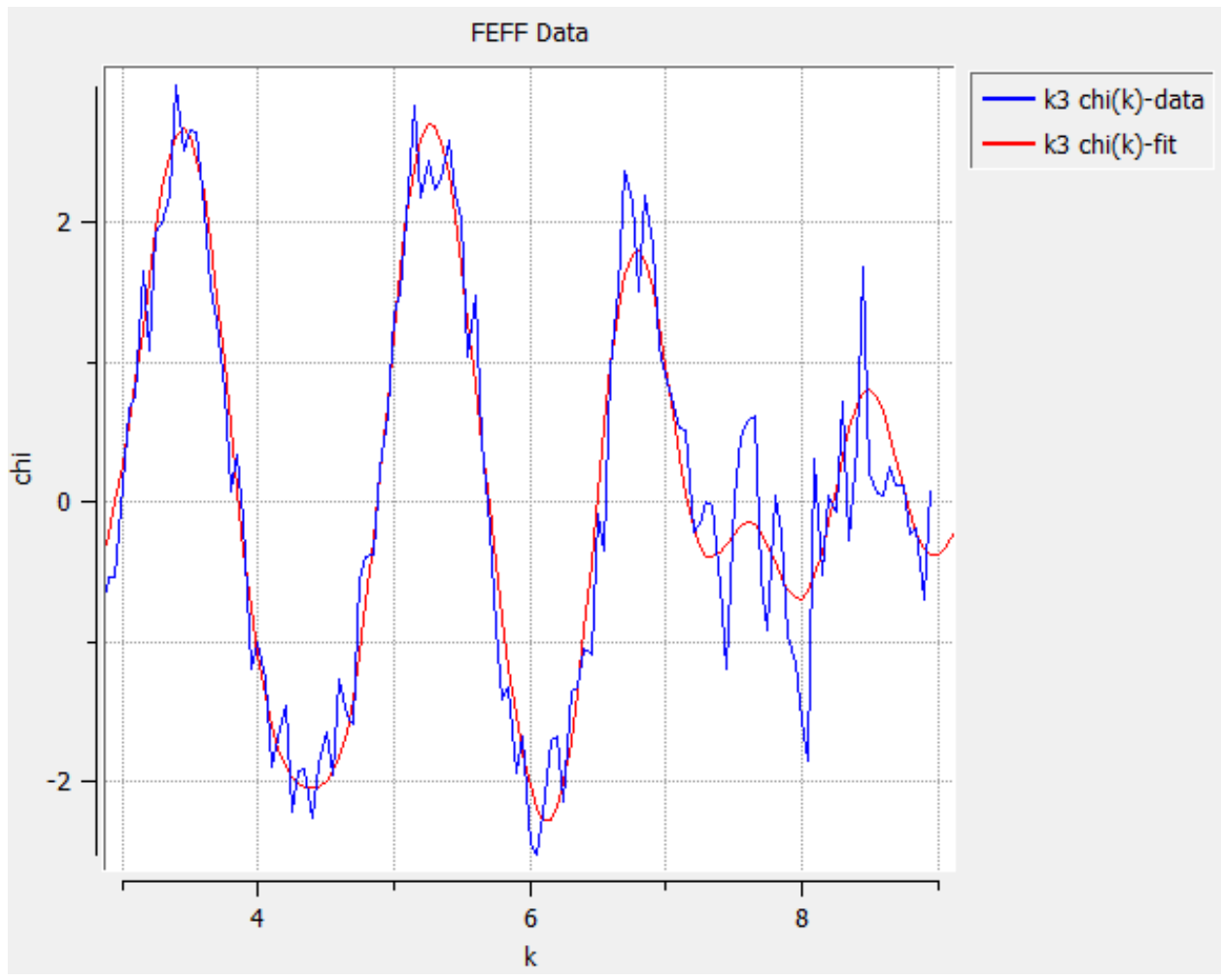

(a)

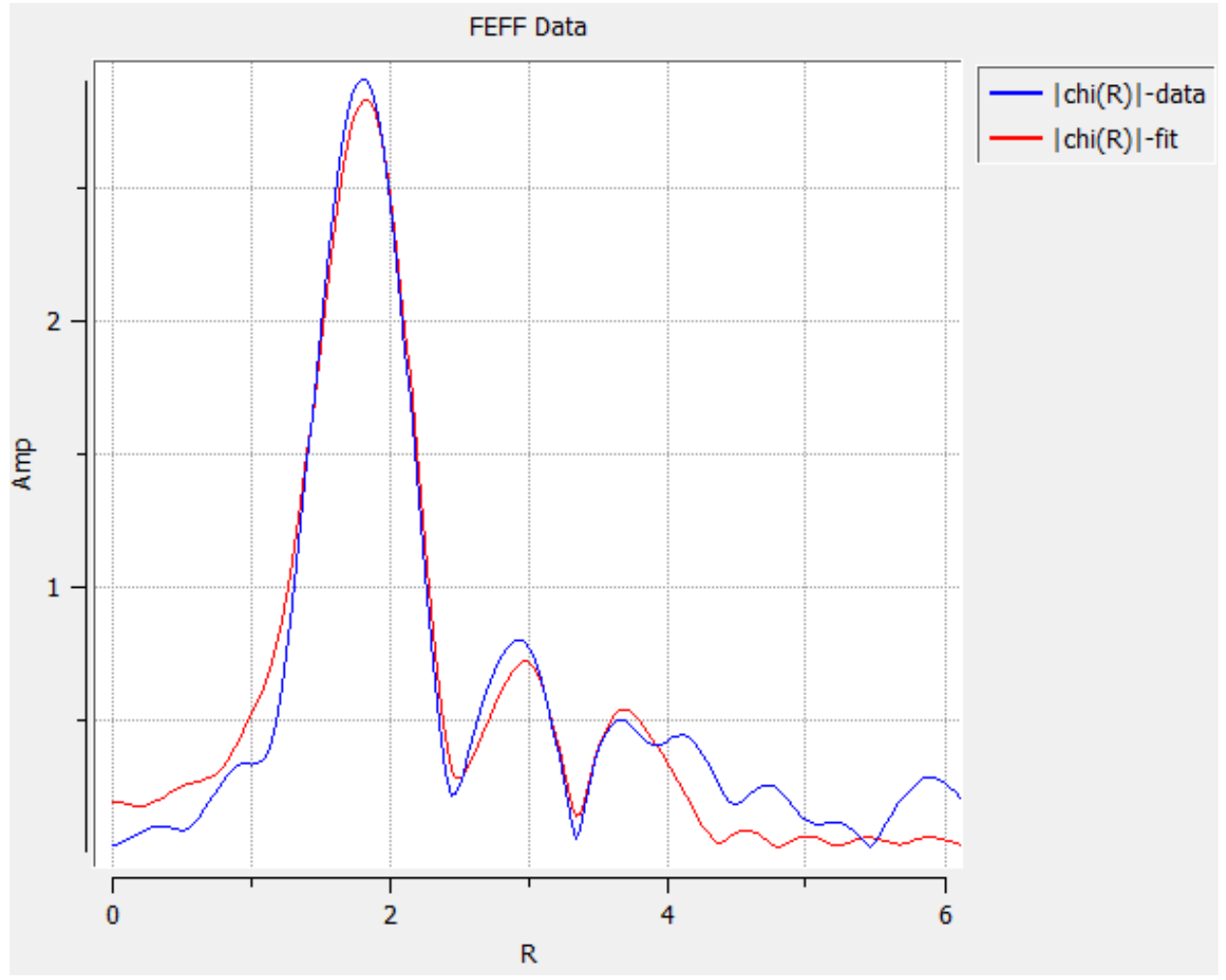



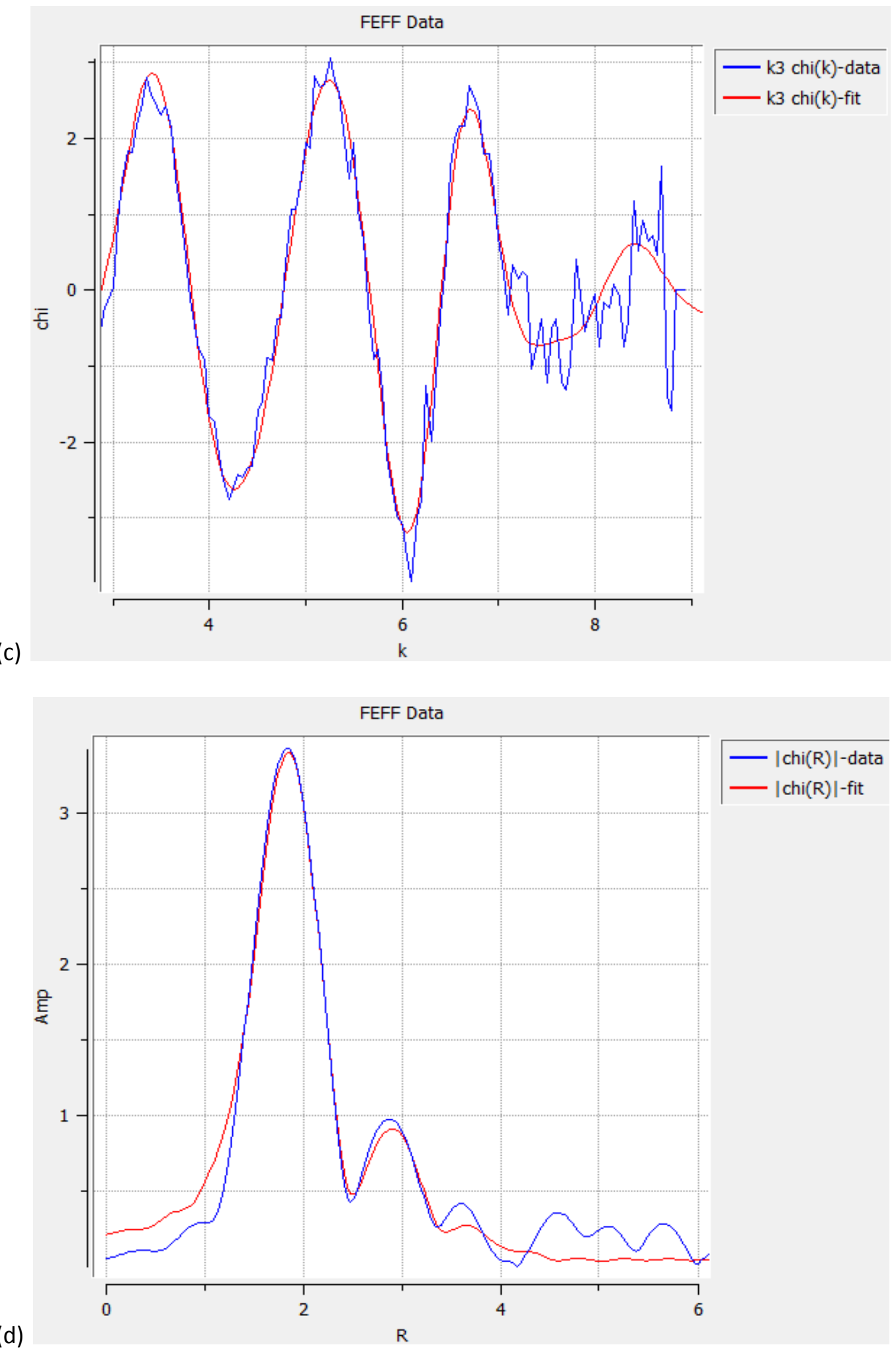

Figure 3: In all plots, Actual data is shown in blue, while a fit using bonds to oxygen, phosphorus and iron is shown in red. (a) P101 EXAFS chi vs. k data. (b) P101 EXAFS Fourier transformed data plotting amplitude versus bond distance in angstroms. (c) P102 EXAFS chi vs. k data. (d) P102 EXAFS Fourier transformed data plotting amplitude versus bond distance in angstroms. 


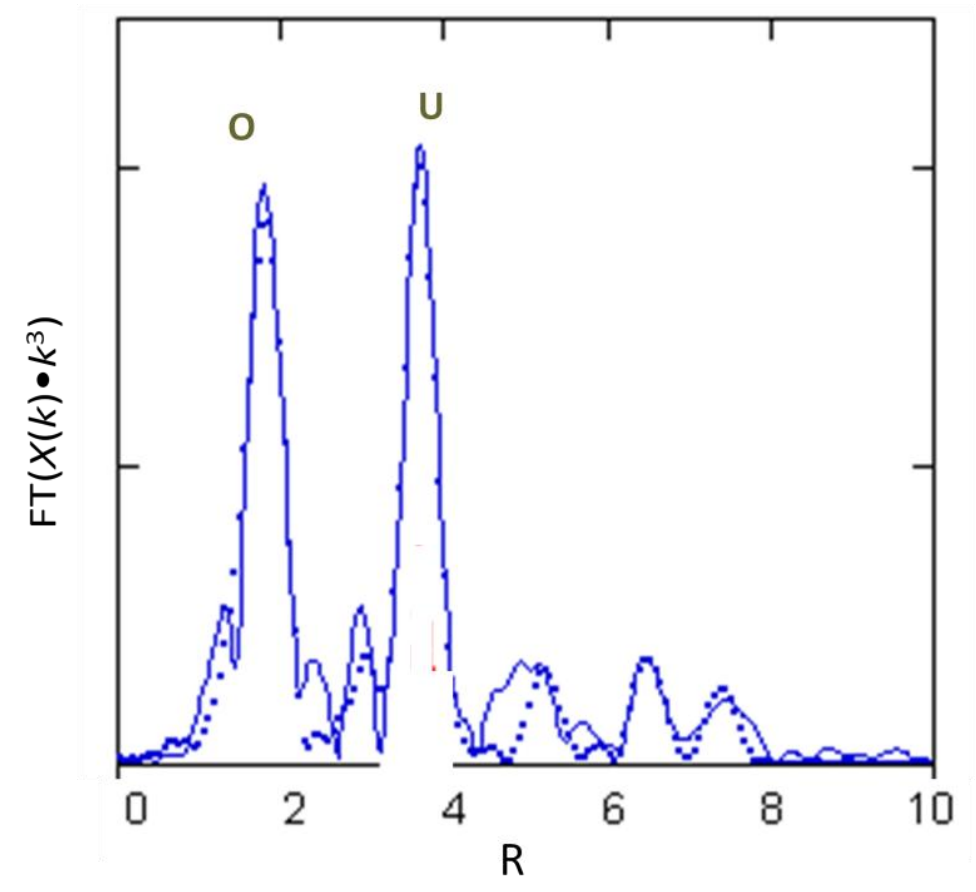

\section{Uraninite}

Figure 5: Uraninite EXAFS spectrum. Noticeable features include a large peak at 3.87 angstroms representing a uranium-uranium bond, as well as large peak at approximately 2 angstroms representing a uranium-oxygen bond. 